\title{
Poluição do meio ambiente marinho: um breve panorama dos princípios, instrumentos jurídicos e legislação brasileira
}

\author{
Pollution of the marine environment: a brief overview of \\ principles, legal instruments and brazilian legislation
}

\author{
Jan Fernandes Aslan ${ }^{1}$, Augusto Eduardo Miranda Pinto ${ }^{2}$ e Manildo Marcião de Oliveira ${ }^{3}$
}

1 Engenheiro Químico pela Universidade Federal Fluminense e Engenheiro de Petróleo pela Universidade Estadual do Norte Fluminense.
Mestrando do Programa de Pós Graduação em Engenharia Ambiental do Instituto Federal Fluminense. E-mail: jfaslan@hotmail.com
2 Graduação em Direito pela Universidade do Estado do Rio de Janeiro, Mestrado em Educação Tecnológica pelo Centro Federal de
Educação Tecnológica Celso Suckow da Fonseca, Mestrado em Direito pela Universidade do Estado do Rio de Janeiro, Doutorado em
Direito da Cidade pela Universidade do Estado do Rio de Janeiro. Professor da Faculdade Cenecista Rio das Ostras, Auditor Fiscal do
Trabalho da Delegacia Regional do Trabalho-RJ, Professor Titular do Instituto Federal Fluminense. E-mail: augustoepinto@gmail.com
3 Graduação em Biologia pela Faculdade da Região dos Lagos, Mestrado em Biologia (Biociências Nucleares) pela Universidade do Esta-
do do Rio de Janeiro e Doutorado em Biologia (Biociências Nucleares) pela Universidade do Estado do Rio de Janeiro. Professor de En-
sino Básico, Técnico e Tecnológico do Instituto Federal de Educação, Ciência e Tecnologia Fluminense. E-mail: manildodpicf@gmail.com

RESUMO: A poluição marinha tem sido razão de preocupação de toda sociedade mundial. Os níveis de poluição provocados pela ação descontrolada da humanidade têm levado a Organização das Nações Unidas a organizar diversas Convenções e Tratados para disciplinar o uso do recurso do mar e a prevenção da poluição ambiente marinho. Foram evocados princípios ambientais como da precaução e do poluidor-pagador na criação de um conjunto de regras de forma a contribuir efetivamente para diminuição dos riscos de poluição marinha em vários aspectos. O Brasil tem estabelecido importante legislação calcada nos resultados dos tratados e acordos assinados dos quais participou.

Palavras-chave: Poluição Marinha. Princípio da Precaução. Princípio do Poluidor-Pagador. Legislação Ambiental. Direito No Mar.

ABSTRACT: Marine pollution has been a concern of every society in the world. The levels of pollution caused by the uncontrolled action of mankind have led the United Nations Organization to organize various Conventions and Treaties to discipline the use of the sea resource and the prevention of pollution of the marine environment. Environmental principles such as precautionary and polluter-pays principles have been invoked in creating a set of rules in order to effectively contribute to reducing the risks of marine pollution in several respects. Brazil has established important legislation based on the results of the signed treaties and agreements in which it participated.

Keywords: Marine Pollution. Precautionary Principle. Polluter-Pays Principle.

Environmental Legislation. Law at Sea.

Sumário: Introdução - 10 Porquê da Poluição Marinha: A Tragédia dos Comuns - 2 Convenções e Tratados Internacionais - 3 Princípio do Poluidor-Pagador no Ambiente Marinho - 40 Princípio da Precaução no Ambiente Marinho - 5 Legislação Sobre Poluição Marinha no Brasil - Considerações Finais - Referências.

Planeta Amazônia: Revista Internacional de Direito Ambiental e Políticas Públicas 


\section{INTRODUÇÃO}

A preservação da qualidade de vida do planeta passa necessariamente pelo cuidado com os oceanos, pois são os reguladores do clima no planeta, além de serem fontes de riquezas e alimentos. A poluição marinha é consequência do seu uso indiscriminado e do falso pensamento de que a capacidade do mesmo de receber dejetos e resíduos era ilimitada.

O mar se tornou receptor final de diversos elementos, provenientes de rios, lançamento de esgoto in natura e despejos de navios ou plataformas de petróleo. Os aportes mais comuns em áreas costeiras são os de origem orgânica, oriundos de despejos de esgotos e que são constituídos basicamente de matéria orgânica. Como apresentam nitrogênio e fósforo predominantemente na sua composição, ocorre o crescimento desordenado de microalgas (eutrofização) e o aparecimento de espécies indesejáveis como as cianobactérias.

Além da matéria orgânica encontrada no esgoto e drenagem urbana, outros tipos de contaminantes podem ser encontrados principalmente oriundos de efluentes industriais, como hidrocarbonetos, substâncias inorgânicas e radioativas. A navegação, assim como a exploração de petróleo no mar também, gera diversos tipos de poluentes na água, como hidrocarbonetos de petróleo, introdução de espécies exóticas pelas águas de lastro e elementos químicos acumulados nos sedimentos e liberados pelo processo de dragagem nos portos que dão apoio às atividades marítimas.

A preocupação com a poluição do meio ambiente marinho assumiu outra perspectiva a partir da década de 1970, quando incidentes marítimos de grande relevância envolvendo principalmente petroleiros, assolaram as costas de países da Europa e dos Estados Unidos. Várias Conferências foram convocadas a partir desta década gerando inúmeras regras e normas que visavam aumentar a segurança na navegação e diminuir a poluição do meio ambiente marinho.

Este artigo apresenta as tentativas do Homem em buscar uma solução para a questão da poluição do ambiente marinho, expondo os princípios ambientais norteadores aplicados à poluição marinha, algumas das principais convenções internacionais direcionadas ao tema e a legislação brasileira voltada para a proteção do meio ambiente marinho.

\section{PORQUÊ DA POLUIÇÃO MARINHA: A TRAGÉDIA DOS COMUNS}

Uma possível resposta sobre as razões pelo qual o homem polui está no que o ecologista Garret Hardin chamou, em 1968, de a "Tragédia dos Comuns" (Tragedy of the Commons). Ele apontava como consequência natural do crescimento populacional, a criação de um verdadeiro efeito trágico no uso dos recursos naturais considerados de uso comum, isto é, aqueles sob os quais não haveria propriedade privada definida sobre os mesmos e que, portanto, haveria livre acesso ao seu uso, seja por consumidores, seja por produtores (DINIZ; ARRAES, 2001).

Para evitar tal tragédia, Hardin concluiu que recursos de uso comum deveriam ser privatizados ou que normas governamentais a usos e usuários sejam instituídas. Mas seu mode- 
lo é incompleto. Suas conclusões sobre a tragédia inevitável baseiam-se em seus a pressupostos sobre livre acesso e ausência de restrições aos comportamentos individuais. Negligencia o importante papel de arranjos institucionais que geram exclusão e regulação de uso. No caso, funcionam como propriedade comunal, onde os recursos são manejados por uma comunidade identificável de usuários interdependentes (FEENY et al., 1990).

Além disso, a lógica da propriedade comunal também pode ser aplicada a recursos globais, onde é mais difícil prevenir tragédias. O caso da poluição por petróleo em alto mar, que envolveu várias convenções internacionais desde 1954 e levou a reduções dos derramamentos acidentais de petróleo na década de 1980, demonstra que a cooperação internacional pode ser efetiva (FEENY et al., 1990). Com relação a definição de poluição marinha o artigo $1^{\circ}$ da CNUDM determina que é a:

[...] introdução pelo homem, direta ou indiretamente, de substâncias ou energia no meio marinho, incluindo estuários, sempre que a mesma provoque ou possa provocar efeitos nocivos, tais como danos aos recursos vivos e à vida marinha, riscos à saúde do homem, entraves às atividades marinhas, incluindo pesca e outras utilizações legítimas do mar, no que se refere à sua utilização ou deterioração dos locais de recreio (Decreto no 99.165/1990, art. 1ํ).

Particularmente no mundo marítimo, o conceito de uso comum global desempenha um papel importante em todos os tipos de regulamentos e legislações internacionais ao indicar claramente quem possui (em quais partes) os oceanos. A CNUDM/1982 é o tratado internacional mais importante que regulamenta a utilização dos mares e oceanos do mundo.

\section{CONVENÇÕES E TRATADOS INTERNACIONAIS}

Várias convenções internacionais relativas à prevenção da poluição marinha ocorreram ao longo dos anos, tendo como marco inicial a Convenção Internacional para a Prevenção da Poluição do Mar por Óleo (OILPO), em 1954. Esta convenção tratou basicamente da poluição gerada pelas operações rotineiras dos navios-tanques, que era tida como a principal causa de poluição por navios (HECK, 2012).

O derramamento de 120.000 toneladas de óleo cru no Canal da Mancha em 1967 pelo navio Torrey Canyon desnudou uma situação que necessitava de inclusão e atenção na legislação internacional: a compensação por danos causados por poluição por óleo transportado como carga em navios (CABRAL, 2010).

Uma conferência foi convocada para a cidade de Bruxelas, na Bélgica, em 1969, para a adoção da Convenção Internacional sobre Responsabilidade Civil em Danos Causados por poluição por Óleo, que ficaria conhecida por CLC/69 e que procurou fixar as regras que deveriam valer internacionalmente, sobre a responsabilidade do proprietário do navio, sobre a constituição de fundo relativo à sua responsabilidade, sobre apresentação de reclamações e compensação correlatas a derramamento de óleos de navios (SILVA, 2008).

Paralelamente a CLC/69, ocorreu a Convenção relativa à Intervenção em Alto-Mar nos 
Casos de Baixas por Poluição por Óleo que reconheceu aos Estados costeiros o direito de intervir em alto-mar e de tomar medidas para proteger os interesses ameaçados pela poluição decorrente de acidente de navegação (HECK, 2012).

A partir da década de 1970 as preocupações com o meio ambiente marinho tomaram maior relevância no cenário mundial. A Convenção Internacional para a Prevenção da Poluição por Navios (MARPOL) teve por propósito o estabelecimento de regras para a completa eliminação da poluição intencional do meio ambiente por óleo e outras substâncias danosas oriundas de navios, bem como a minimização da descarga acidental daquelas substâncias no ar e no meio ambiente marinho.

A Convenção MARPOL, realizada em Londres, em 1973, foi posteriormente emendada pelo Protocolo de 1978, passando a ser conhecida como MARPOL 73/78. Mais adiante foi também adotado o Protocolo de 1997, que acrescentou o Anexo VI à Convenção (MARPOL, 1973/1978).

A MARPOL contém 6 anexos que se preocupam com a prevenção de diferentes formas de poluição marinha por navios, sendo: Anexo I - Regulação para a prevenção de poluição por óleo combustível; Anexo II - Regulação para a prevenção de poluição por carga líquida nociva transportada a granel; Anexo III - Regulação para prevenção de poluição por substâncias nocivas carregadas em embalagens; Anexo IV - Regulação para prevenção de poluição por esgoto; Anexo V - Regulação para descarte de lixo dos navios e Anexo VI - Prevenção de poluição do ar. Para que uma nação se torne parte da MARPOL deve aceitar os Anexos I e II. Os outros anexos são de adesão voluntária (MARPOL, 1973/1978).

A MARPOL 73/78 consagra avanços em relação a instrumentos jurídicos anteriores relativos à poluição marítima. $O$ conjunto de regras rigorosas e coerentes contribui efetivamente para a diminuição dos riscos de poluição marinha por acidente ou descarga. Contudo, é possível constatar facilmente que exceções previstas na Convenção representam uma abertura para o descarte de hidrocarbonetos pelos navios.

Outro ponto observado, é que a MARPOL 73/78 não estabeleceu disposições mais severas quanto às sanções em caso de violação da regulamentação relativa ao descarte de hidrocarbonetos. A Convenção limita-se a obrigar os Estados-parte a reportarem casos de acidentes que acarretem ou possam acarretar o descarte de substâncias nocivas (HECK, 2012). No Brasil, a Convenção concluída em 1973 e seu Protocolo em 1978 e suas Emendas de 1984 só foram promulgados pelo Decreto $\mathrm{n}^{\circ} 2.508$, de 04 de março de 1998.

As regras do Direito internacional do Meio Ambiente tendente à prevenção da poluição e proteção do meio ambiente marinho contra a poluição representam uma construção piramidal. No vértice da pirâmide encontra-se a Convenção de Montego Bay sobre o Direito do Mar (Jamaica, 1982), que configura um tratado universal de abrangência geral do conjunto da matéria (MARTINS, 2008).

Considerada como um dos mais complexos tratados da história das Nações Unidas, a CNUDM, assinada pelos Estados-Partes, na cidade de Montego Bay, representa o último Umbrella Treaty (tratado guarda-chuva) firmado pelos países. O objetivo maior da CNUDM é criar um regime universal de regulação de todos os assuntos relativos aos oceanos, bem como 
dos assuntos correlatos aos ambientes marinhos (MARTINS, 2015).

No Brasil, a implementação da CNUDM vem sendo efetivada pela criação de uma série de programas e planos de integração, entre eles, o Plano Nacional de Gerenciamento Costeiro, instituído pela Lei no 7.661, de 16 de maio de 1988, do qual se originou o Programa Nacional de Gerenciamento Costeiro, coordenado pelo Ministério do Meio Ambiente, e o Programa de Avaliação de Potenciais Sustentáveis de Captura de Recursos Vivos na Zona Econômica Exclusiva (PORTO, 2000).

Na Convenção das Nações Unidas sobre o Meio Ambiente e Desenvolvimento (CNUMAD), em 1992, assinada no Rio de Janeiro por 170 Estados tem na Agenda 21, um dos documentos da Convenção, em seu capítulo 17 a previsão da proteção do meio ambiente marinho, sendo intitulado Proteção dos Oceanos, de Todos os tipos de Mares - inclusive Mares Fechados e Semifechados - e das Zonas Costeiras, e Proteção, Uso Racional e Desenvolvimento de seus recursos vivos.

\section{O PRINCÍPIO DO POLUIDOR-PAGADOR NO AMBIENTE MARINHO}

O princípio do poluidor-pagador obriga a empresa poluidora, não só a reparação do dano causado, como também, ao custeio de medidas repressivas e preventivas; constituindo um verdadeiro desestímulo à prática de ações nocivas ao meio ambiente uma vez que, configurado o dano ambiental, será a própria empresa poluidora quem custeará os encargos da recuperação ambiental (HOLDER; CÂMARA, 2014).

Faz-se relevante esclarecer alguns pontos acerca do princípio do poluidor-pagador: Primeiramente, ele não constitui um salvo conduto para que determinadas empresas, que possuem capacidade econômica para arcar com o ônus da reparação, possam poluir demasiadamente. Pelo contrário, o princípio do poluidor-pagador deve ser associado à ideia de prevenção do dano ecológico, uma vez que busca obrigar o potencial poluidor a adotar postura preventiva, que impeça a produção do dano ao meio ambiente (HOLDER; CÂMARA, 2014).

O princípio do poluidor-pagador é um imperativo de segurança marítima que obriga a reparação do dano ambiental, uma obrigação que deverá ser entendida como a mais completa reposição do estado em que se encontrava o local antes da ocorrência do dano, ou seja, uma reparação que tenha em conta os três níveis da biodiversidade: a diversidade genética, a diversidade das espécies e a diversidade dos ecossistemas, em conformidade com a Convenção sobre a Diversidade Biológica, de 1992 (ABREU, 2011).

Em 2008, o princípio do poluidor-pagador foi aplicado no caso da poluição provocada pelo petroleiro Erika. O Tribunal de Paris decidiu condenar a empresa TOTAL S.A. que fretou o petroleiro, bem como o armador, o gestor do petroleiro e a empresa italiana RINA a pagar 154 milhões de euros ao Estado francês, 38 milhões de euros às regiões e municípios franceses atingidos pelas 20 mil toneladas de óleo derramado pelo Erika.

O Tribunal de Paris entendeu que a TOTAL S.A. deveria ser responsabilizada pelo dano ambiental uma vez que fretou o Erika para transportar óleo para Itália, com conhecimento de que este petroleiro tinha quase 25 anos o que revela uma falta de prudência, tendo a polui- 
ção ocorrido no decorrer desta viagem.

\section{O PRINCÍPIO DA PRECAUÇÃO NO AMBIENTE MARINHO}

A fim de desenvolver políticas efetivas em relação ao meio ambiente, é necessário ter em mãos os melhores dados científicos, especialmente quanto a sua precisão. Entretanto, ao lado de poucas certezas, pairam muitas incertezas científicas. Estas incertezas têm historicamente dificultado muito a criação de leis internacionais de proteção ao meio ambiente.

Para evitar uma paralisia causada pela incerteza, alguns instrumentos de direito internacional de proteção ao meio ambiente criados a partir dos anos 1980 têm permitido os Estados Partes a proceder termos de um precautionary approach. Esta abordagem foi pioneira na legislação ambiental alemã durante os anos 1970 e 1980, onde foi denominada de "princípio da precaução" (MORE, 2012).

Este princípio seria, portanto, a garantia contra os riscos potenciais, pois caso não haja certeza a respeito do impacto ambiental a ser ocasionado por determinada ação antrópica, tal atividade deveria ser cessada até que sejam produzidos novos estudos e se tenha a certeza sobre todas as suas consequências, riscos e possíveis danos provocados ao meio ambiente (MARTINS, 2015).

A ideia da precaução no Direito marítimo surgiu da necessidade de conter os elevados níveis de poluição marinha provocados pela crença errada de que o mar tinha uma capacidade infinita de assimilar substâncias poluentes. A tese da capacidade de assimilação, com que tradicionalmente se lidava com a degradação ambiental, foi-se revelando incapaz de quantificar a capacidade de absorção de um dado recurso ou sistema ambiental. Os acidentes trágicos causadores de graves danos no ambiente marinho revelou os limites da capacidade do mar em absorver elementos poluentes de consequências inaceitáveis (RIBEIRO, 2011).

O princípio da precaução encontra-se previsto na Convenção de Paris para a Proteção do Meio Ambiente Marinho do Atlântico Nordeste, de 1992, da qual o Brasil não faz parte, e que dispõe sobre quais medidas devem ser tomadas quando existem motivos razoáveis de riscos para a saúde humana ou danos aos ecossistemas para introdução de substâncias no meio marinho (FREITAS, 2009).

\section{LEGISLAÇÃO SOBRE POLUIÇÃO MARINHA NO BRASIL}

Embora o artigo 225 da Constituição da República Federativa do Brasil (CRFB), de 1988 não tenha referência sobre proteção ao meio ambiente marinho, as suas determinações também se aplicam à preservação do mar. Quando o inciso VII do $\S 1^{\circ}$ trata da proteção à fauna, também se inclui a fauna marinha. Além do art. 225, cumpre lembrar que são bens da União os recursos naturais da plataforma continental e da zona econômica exclusiva, o mar territorial e os terrenos de marinha (art. 20, incisos V, VI e VII) e que compete a ela, exclusivamente, legislar sobre direito marítimo e defesa marítima, conforme art. 22, incisos I e XXVIII e, em concorrência com os Estados, sobre proteção do meio ambiente e controle da polui- 
ção, na forma do art. 24, inciso VI (FREITAS, 2009).

A primeira legislação brasileira que versou sobre a questão da poluição marinha foi a Lei $n$ - 5.357, de 17 de novembro de 1967, a qual estabelecia penalidades para embarcações e terminais marítimos ou fluviais que lançarem detritos ou óleos em águas brasileiras. Foi revogada pela Lei no 9.966 de 28 de abril de 2000 e que "dispõe sobre a prevenção, o controle e a fiscalização da poluição causada por lançamento de óleo e outras substâncias nocivas ou perigosas em águas sobre jurisdição nacional”. 0 art. $3^{\circ}$ desta lei, classifica as águas como interiores e marítimas, tendo, portanto atuação, em todas as águas sob jurisdição nacional. 0 Decreto no 4.136, de 20 de fevereiro de 2002,

dispõe sobre a especificação das sanções aplicáveis às infrações às regras de prevenção, controle e fiscalização da poluição causada por lançamento de óleo e outras substâncias nocivas ou perigosas em águas sob jurisdição nacional, prevista na Lei № 9.966 .

O Decreto classifica mais claramente o que são águas marítimas em termos de mar territorial (até 12 milhas marítimas), zona econômica exclusiva (de 12 a 200 milhas marítimas) e águas sobrejacentes à plataforma continental que seriam aquelas que ultrapassam os limites da zona econômica exclusiva. O Brasil pleiteia junto a Organização das Nações Unidas a extensão dos limites de sua plataforma continental, o que significaria ampliar o limite da zona econômica exclusiva de 200 para 350 milhas marítimas.

Como parte integrante da Política Nacional do Meio Ambiente e da Política Nacional para os Recursos do Mar, foi instituído o Plano Nacional de Gerenciamento Costeiro pela Lei $n^{\circ} 7.661$, de 16 de maio de 1988 e regulamentado pelo Decreto $n^{\circ} 5.300$ de 07 de dezembro de 2004, no qual "dispõe sobre regras de uso e ocupação da zona costeira e estabelece critérios de gestão da orla marítima". Este decreto, que define normas gerais visando a gestão ambiental da zona costeira do País, estabelece no art. $6^{\circ}$ e inciso IV, como um dos seus objetivos, "o controle sobre agentes causadores de poluição ou degradação ambiental que ameacem a qualidade de vida na zona costeira.

A Lei no 9.537, de 11 de dezembro de 1997 que "dispõe sobre a segurança do tráfego aquaviário em águas sob jurisdição nacional", também aborda aspectos quanto à prevenção da poluição marinha no que diz respeito a inspeções e vistorias no art. $2^{\circ}$, incisos VII e XXI.

Quanto às sanções penais e administrativas de atos que danificam o maio ambiente, a Lei no 9.605, de 12 de fevereiro de 1998, conhecida como a Lei de Crimes Ambientais, deu maior suporte na prevenção de todo tipo de poluição. O que anteriormente eram classificados somente como contravenções penais, passaram a se tornar crimes a partir da nova lei. Um outro avanço desta lei foi prever penalidades também para pessoas jurídicas, além da possibilidade de reparação ao dano causado.

Devido a legislação ser por muitas vezes dispersa e pouco detalhada, se faz necessário que órgãos competentes criem normas, que podem ser resoluções, portarias ou instruções normativas, a fim de inserir particularidades necessárias para disciplina da matéria envolvida. Nas questões ambientais e particularmente do âmbito da poluição marinha, o Conselho Na- 
cional do Meio Ambiente (CONAMA) é o órgão de maior relevância na edição destas normas, que são chamadas de Resoluções. As principais Resoluções do CONAMA relativo ao Direito Marinho são as seguintes:

- Resolução CONAMA n 393/2007, dispõe sobre o descarte contínuo de água de processo ou de produção em plataformas marítimas de petróleo e gás natural e dá outras providências. Esta Resolução estabelece um padrão para descarte de óleos e graxas e define parâmetros de monitoramento da água a ser descartada e é produzida junto com o petróleo, devendo ter média aritmética simples mensal de óleos e graxas de até $29 \mathrm{mg} / \mathrm{L}$, com valor máximo diário de $42 \mathrm{mg} / \mathrm{L}$.

- Resolução CONAMA n 398/2008, dispõe sobre o conteúdo mínimo do Plano de Emergência Individual para incidentes de poluição por óleo em águas sob jurisdição nacional, originados em portos organizados, instalações portuárias, terminais, dutos, sondas terrestres, plataformas e suas instalações de apoio, refinarias, estaleiros, marinas, clubes náuticos e instalações similares e orienta sua elaboração. Esta Resolução anula e substitui a Resolução n 293/2001. Exige a apresentação do Plano de Emergência Individual na apresentação da licença ambiental e sua aprovação está condicionada a concessão da Licença de Operação, de Licença Prévia de Perfuração e da Licença Prévia de Produção para Pesquisa.

- Resolução CONAMA n 430/2011, dispõe sobre condições e padrões de lançamento de efluentes, complementa e altera a Resolução no 357, de 17 de março de 2005, do Conselho Nacional do Meio Ambiente - CONAMA. Os padrões estabelecidos nesta Resolução não distinguem o corpo receptor dos efluentes, no entanto, quando a disposição de efluentes por emissário submarino estiver em desacordo com esta Resolução, poderá ser autorizada pelo órgão ambiental desde que haja um estudo ambiental contendo o estudo de dispersão na zona de mistura em dois cenários (com os valores preconizados na Resolução e com os valores propostos pelo empreendedor), além do programa de monitoramento ambiental.

- Resolução CONAMA n 472/2015, dispõe sobre o uso de dispersantes químicos em incidentes de poluição por óleo no mar. Esta Resolução anula e substitui a Resolução n 269/2000. Esta Resolução se caracterizava por ser mais descritiva, estabelecendo toda a metodologia de execução na aplicação dos dispersantes no meio ambiente marinho. Já a Resolução $n^{\circ}$ 472/2015 está mais estruturada na determinação de critérios e diretrizes do uso dos dispersantes no tratamento do óleo derramado no mar.

Outro importante órgão que determina normas infralegais no auxílio a prevenção da poluição marinha é a Diretoria de Portos e Costas (DPC) da Marinha do Brasil. Neste aspecto, pode-se destacar a Normam 20/DPC, que é a Norma da Autoridade Marítima para o Gerenciamento da Água de Lastro de Navios. Esta norma visa a implementação de métodos e procedimentos para o gerenciamento da água de lastro com objetivo de reduzir ao mínimo a introdução de organismos aquáticos exóticos e agentes patogênicos nas águas jurisdicionais brasileiras. 


\section{CONSIDERAÇÕES FINAIS}

O crescimento populacional, associado ao desenvolvimento, a exploração dos recursos do mar e a crença na infinitude destes recursos pelo homem, tem alterado significativamente os níveis de poluição nos mares. A partir desta percepção, e ao reconhecer que o mar, por ser um recurso de uso comum, foram realizadas convenções e tratados internacionais ao longo dos últimos 50 anos na tentativa de criar mecanismos de controle e prevenção da poluição marinha. Neste contexto, o Brasil tem ampliado seu arcabouço jurídico, com leis e políticas públicas associadas a setores regulamentados.

Os princípios ambientais se apresentaram como consequências das discussões ocorridas durante as Convenções Internacionais do Meio Ambiente, servindo como linha mestra para as suas declarações. As declarações em tratados internacionais nortearam as diretrizes da legislação ambiental brasileira. Com uma diplomacia atuante e uma necessidade de maior inserção internacional, o Brasil participou ativamente destas discussões, embora seja observado que as promulgações desses tratados, por meio de decretos presidenciais, se dão após um longo período de tempo.

Apesar da legislação brasileira, no âmbito da poluição do meio ambiente marinho ser reconhecidamente rigorosa, sua aplicabilidade se mostra fragilizada pelos poucos recursos dos órgãos fiscalizadores ambientais no controle e na prevenção da poluição marinha. Para atenuar sua capacidade de fiscalização, o órgão ambiental tem cobrado do empreendedor uma gestão auto regulatória e responsável pelos riscos de sua atividade, no qual são cobrados programas de monitoramento e controle ambientais como parte integrante para manutenção das licenças ambientais.

Também, a responsabilidade do empreendedor por danos causados ao meio ambiente marinho, a partir da aplicação de multas de valores irrisórios, induzem um sentimento ao agente poluidor de que é mais oneroso prevenir a poluição do que propriamente poluir.

No aspecto da aplicação de multas, existe um projeto de lei (4286/2016), motivado pelo acidente da Samarco em Mariana/MG, que visa alterar o art. 75 da Lei de Crimes, aumentando o valor máximo a ser pago pelo agente poluidor. Um critério mais justo e técnico seria a utilização da valoração ambiental do recurso natural danificado, como parâmetro para a determinação do valor da multa.

Por fim, a legislação brasileira tem sido pautada na prevenção e na responsabilização de danos ambientais como um todo, por meio da aplicação de multas e reparação do dano. São considerados meios importantes para a inibição e controle da poluição, porém deve haver em paralelo maior alcance e percepção da sociedade sobre os riscos iminentes e consequências de um ambiente marinho poluído.

\section{REFERÊNCIAS}

ABREU, L.C. O Princípio do Poluidor-Pagador: Um Imperativo de Segurança Marítima. Direito e Ambiente, Lisboa, $n^{\circ}$ 2/3, 2011. 
BRASIL. Lei $n^{\circ}$ 9.966, de 28 de abril de 2000. Dispõe sobre a prevenção, o controle e a fiscalização da poluição causada por lançamento de óleo e outras substâncias nocivas ou perigosas em águas sob jurisdição nacional e dá outras providências. Disponível em <http://www.planal to.gov.br/ccivil_03/leis/L9966.htm> Acesso em: 10 jul. 2017.

. Decreto $n^{\circ} 4.136$, de 20 de fevereiro de 2002. Dispõe sobre a especificação das sanções aplicáveis às infrações às regras de prevenção, o controle e a fiscalização da poluição causada por lançamento de óleo e outras substâncias nocivas ou perigosas em águas sob jurisdição nacional prevista na Lei $\mathrm{n}^{\circ}$ 9.966, de 28 de abril de 2000, e dá outras providências. Disponível em < http://www.planalto.gov.br/ccivil_03/decreto/2002/D4136.htm> Acesso em: 10 jul. 2017.

. Lei $n^{\circ} 7.661$, de 16 de maio de 1988. Institui o Plano Nacional de Gerenciamento Costeiro e dá outras providências. Disponível em <http://www.planalto.gov.br/ccivil_03/leis/ L7661.htm> Acesso em: 10 jul. 2017.

. Decreto $n^{\circ} 5.300$, de 07 de dezembro de 2004. Regulamenta a Lei $n^{\circ} 7.661$, de 16 de maio de 1988, que institui o Plano Nacional de Gerenciamento Costeiro - PNGC, dispõe sobre regras de uso e ocupação da zona costeira e estabelece critérios de gestão da orla marítima e dá outras providências. Disponível em <http://www.planalto.gov.br/ccivil_03/_Ato20042006/2004/Decreto/D5300.htm> Acesso em: 10 jul. 2017.

. Lei $n^{\circ} 9.537$, de 11 de dezembro de 1997. Dispõe sobre segurança do tráfego aquaviário em águas sobre jurisdição nacional e dá outras providências. Disponível em <http://www. planalto.gov.br/ccivil_03/leis/I9537.htm > Acesso em: 10 jul. 2017.

. Lei $n^{\circ} 9.605$, de 12 de fevereiro de 1998. Dispõe sobre sanções penais e administrativas derivadas de condutas e atividades lesivas ao meio ambiente e dá outras providências. Disponível em <http://www.planalto.gov.br/ccivil_03/leis/L9605.htm> Acesso em: 10 jul. 2017.

. Resolução CONAMA n 393, de 08 de agosto de 2007. Dispõe sobre o descarte contínuo de água de processo ou de produção em plataformas marítimas de petróleo e gás natural e dá outras providências. Disponível em <http://www.mma.gov.br/port/conama/legiabre. cfm?codlegi=541 > Acesso em: 10 jul. 2017.

. Resolução CONAMA n 398 , de 11 de junho de 2008. Dispõe sobre o conteúdo mínimo do Plano de Emergência Individual para incidentes de poluição por óleo em águas sob jurisdição nacional, originados em portos organizados, instalações portuárias, terminais, dutos, sondas terrestres, plataformas e suas instalações de apoio, refinarias, estaleiros, marinas, clubes náuticos e instalações similares e orienta sua elaboração. Disponível em <http://www. mma.gov.br/port/conama/legiabre.cfm?codlegi=575 > Acesso em: 10 jul. 2017.

. Resolução CONAMA $n^{\circ} 430$, de 13 de maio de 2011. Dispõe sobre condições e padrões de lançamento de efluentes, complementa e altera a Resolução no 357, de 17 de março de 2005, do Conselho Nacional do Meio Ambiente - CONAMA. Disponível em <http://www. mma.gov.br/port/conama/legiabre.cfm?codlegi=646> Acesso em: 10 jul. 2017.

. Resolução CONAMA $n^{\circ}$ 472, de 27 de novembro de 2015. Dispõe sobre o uso de dispersantes químicos em incidentes de poluição por óleo no mar. Disponível em <http://www. 
mma.gov.br/port/conama/legiabre.cfm?codlegi=718> Acesso em: 10 jul. 2017.

. Decreto no 99.165, de 12 de março de 1990. Promulga a Convenção das Nações Unidas sobre o Direito do Mar. Disponível em <http://www2.camara.leg.br/legin/fed/decret/ 1990/decreto-99165-12-marco-1990-328535-publicacaooriginal-1-pe.html> Acesso em: 10 jul. 2017.

. Decreto no 2.508, de março de 1998. Promulga o Convenção Internacional para a Prevenção da Poluição Causada por Navios, concluída em Londres, em 2 de novembro de 1973, seu Protocolo, concluído em Londres, em 17 de fevereiro de 1978, suas Emendas de 1984 e seus Anexos Opcionais III, IV e V. Disponível em: <http://www.planalto.gov.br/cci vil_03/decreto/d2508.htm> Acesso em: 12 ago. 2017.

.Lei no 7.661, de 16 de maio de 1988. Institui o Plano Nacional de Gerenciamento Costeiro e dá outras providências. Disponível em <http://www.planalto.gov.br/CCivil_03/leis/ L7661.htm> Acesso em 15 out.2017

.Lei no 5.357, de 17 de novembro de 1967. Estabelece penalidades para embarcações e terminais marítimos ou fluviais que lançarem detritos ou óleo em águas brasileiras, e dá outras providências. Disponível em <http://www.planalto.gov.br/Ccivil_03/leis/19501969/L5357.htm> Acesso em 15 out.2017. (Revogada).

CABRAL, L. J. S. Convenções Internacionais sobre Poluição do Mar por Navios e a Posição do Estado Brasileiro (Dissertação). Universidade Federal do Rio de Janeiro. Rio de Janeiro: UFRJ/ COPPE, 2010.

DINIZ, M. B.; ARRAES, R. A. "Tragédia dos comuns" e o exemplo da pesca da lagosta: abordagens teóricas. Belém, PA, 2001. Disponível em: <http://www.abepro.org.br/biblioteca/ENE GEP2001_TR60_0114.pdf. Acesso em: 16 nov. 2017.

FEENY, D. et al. The Tragedy of the Commons: Twenty-two years later. Human Ecology, v. 18, n. 1, p. 1-19, mar. 1990.

FREITAS, D. P. Poluição marítima: legislação, doutrina e jurisprudência. Ed. Juruá Editora, Curitiba. 2009.

HECK, M. A ação normativa da Organização Marítima Internacional e seus instrumentos em face da poluição marítima por óleo causada por navios. Revista de Direito Internacional, v. 9, n. 3, 2012.

HOLDER, J; CÂMARA, C. G. Poluição Marinha e Responsabilidade Civil nas Atividades OffShore da Indústria do Petróleo. Revista Direito E-nergia, v. 3, n. 1, 2014.

Marinha do Brasil - Diretoria de Portos e Costas: Norma da Autoridade Marítima para o Gerenciamento da Água de Lastro de Navios - Normam 20, 2014. Disponível em: <https://www. dpc.mar.mil.br/sites/default/files/normam20.pdf> Acesso em: 10 jul. 2017

MARPOL 73/78 Convenção Internacional para a Prevenção da Poluição por Navios, 1973. Disponível em: <https://www.ccaimo.mar.mil.br/marpol>. Acesso em: 11 abr. 2017.

MARTINS, E. M. O. Direito marítimo internacional: da responsabilidade internacional pelos danos causados ao meio ambiente marinho. VERBA JURIS-Anuário da Pós-Graduação em Direito, v. 7, n. 7, 2008.

MARTINS, R. O Direito Marítimo e a Questão Ambiental: Análise Acerca dos Princípios da Pre- 
caução e do Poluidor Pagador Como Instrumentos de Efetividade Jurídica no Combate à Poluição do Meio Ambiente Marinho. Revista Aurora, v. 8, n. 01, 2015.

MORE, R. F. A poluição do meio ambiente marinho e o princípio da precaução. Jus Navigandi, 2012.

PORTO, G. E. L. Responsabilidade pela Poluição Marinha. Brasília, n. 12, p. 51-57, set./dez. 2000.

RIBEIRO, L. J. B. R. A relevância do princípio da precaução numa política integrada para o mar. Nação e Defesa, 2011.

SILVA, A. C. L. A evolução do direito internacional do meio ambiente e a construção de um regime jurídico internacional para o mar através do direito marítimo: os incidentes marítimos que provocaram mudanças significativas nas normas de proteção do meio ambiente marinho. 2008. 48 p. Monografia (Especialista em Relações Internacionais). Instituto de Ciência Política e Relações Internacionais, Universidade de Brasília, 2008.

Artigo recebido em 12 de julho de 2017.

Aprovado em 24 de abril de 2018. 